Editorial Manager(tm) for Social Psychiatry and Psychiatric Epidemiology

Manuscript Draft

Manuscript Number: SPPE-D-08-00002R1

Title: Individual Unmet Needs for Care: are they sensitive as outcome criterion for the effectiveness of mental health services interventions?

Article Type: Original Article

Keywords: need for care; schizophrenia; routine outcome assessment; community mental health care

Corresponding Author: Prof. Durk Wiersma, PhD

Corresponding Author's Institution: University Medical Center Groningen; University of Groningen

First Author: Durk Wiersma, PhD

Order of Authors: Durk Wiersma, PhD; Rob van den Brink, PhD; Kerstin Wolters, MSc; Rosemarie McCabe; Jens Bullenkamp; Lars Hansson; Christoph Lauber; Rafael Martinez-Leal; Wulf Rössler; Hans Salize; Bengt Svensson; Francisco Torres-Gonzales; Donna J Wright; Stefan Priebe

Abstract: Background: Mental health interventions should demonstrate an effect on patients' functioning as well as his/her needs, in particular on unmet needs whose assessment depends on the perspective of either the patient or the clinician. However, individual met and unmet needs appear to change over time, qualitatively and quantitatively, raising questions about their sensitivity to change and about the association between level of needs and treatment.

Methods: Data on baseline and follow-up need assessment in community mental health services in four European countries in the context of a cluster randomised trial on a novel mental health service intervention were used, which involved 102 clinicians with key worker roles and 320 patients with schizophrenia or related psychotic disorders. Need assessment was performed with the Camberwell Assessment of Needs Short Appraisal Schedule (CANSAS) among patients as 
well as clinicians. Focus is the sensitivity to change in unmet needs over time as well as the concordance between patient and clinician ratings and their relationship with treatment condition. Results: At follow-up 294 patients (92\%) had a full need assessment, while clinician rated needs were available for 302 patients (94\%). Generally, the total number of met needs remained quite stable, but unmet needs decreased significantly over time, according to patients as well as to clinicians. Sensitivity to change of unmet needs is quite high: about two third of all unmet needs made a transition to no or met need, and more than half of all unmet needs at follow-up were new. Agreement between patient and clinician on unmet needs at baseline as well as follow-up was rather low, without any indication of a specific treatment effect.

Conclusions: Individual unmet needs appear to be quite sensitive to change over time but as yet less suitable as outcome criterion of treatment or specific interventions.

Response to Reviewers: see response to letter of editor 
1

2

3

31 December 2007 submitted to Social Psychiatry and Psychiatric Epidemiology

\section{Individual Unmet Needs for Care: are they sensitive as outcome criterion for the effectiveness of mental health services interventions?}

\section{Short title: Unmet Needs for Care as outcome criterion}

Durk Wiersma ${ }^{1}$, Rob van den Brink ${ }^{1}$, Kerstin Wolters ${ }^{1}$, Rosemarie McCabe ${ }^{2}$, Jens Bullenkamp ${ }^{5}$, Lars Hansson ${ }^{4}$, Christoph Lauber ${ }^{6}$, Rafael Martinez-Leal ${ }^{3}$, Wulf Rössler ${ }^{6}$, Hans Salize ${ }^{5}$, Bengt Svensson ${ }^{4}$, Francisco Torres-Gonzales ${ }^{3}$, Donna J. Wright ${ }^{2}$, Stefan Priebe $^{2}$

From the ${ }^{1}$ University Psychiatric Centre, University Medical Center Groningen, University of Groningen, The Netherlands; the ${ }^{2}$ Unit for Social and Community Psychiatry, Queen Mary University of London, UK; the ${ }^{3}$ Department of Psychiatry, University of Granada, Granada, Spain; ${ }^{4}$ University of Lund, Lund, Sweden; ${ }^{5}$ Central Institute for Mental Health, Mannheim, Germany; the ${ }^{6}$ Psychiatric University Hospital, Liverpool, UK

Correspondence to Dr. D.Wiersma at the University Psychiatric Centre, University Medical Center Groningen, P.O.Box 30.001, 9700 RB Groningen, The Netherlands

Tel +31503613839

Fax +31503619722

durk.wiersma@med.umcg.nl

Funding/Support: The study was funded by the Research Directorate of the European Commission within the Framework Programme 5 (QLG5-CT-2002-01938). 


\section{Abstract}

Background: Mental health interventions should demonstrate an effect on patients' functioning as well as his/her needs, in particular on unmet needs whose assessment depends on the perspective of either the patient or the clinician. However, individual met and unmet needs appear to change over time, qualitatively and quantitatively, raising questions about their sensitivity to change and about the association between level of needs and treatment.

Methods: Data on baseline and follow-up need assessment in community mental health services in four European countries in the context of a cluster randomised trial on a novel mental health service intervention were used, which involved 102 clinicians with key worker roles and 320 patients with schizophrenia or related psychotic disorders. Need assessment was performed with the Camberwell Assessment of Needs Short Appraisal Schedule (CANSAS) among patients as well as clinicians. Focus is the sensitivity to change in unmet needs over time as well as the concordance between patient and clinician ratings and their relationship with treatment condition.

Results: At follow-up 294 patients (92\%) had a full need assessment, while clinician rated needs were available for 302 patients (94\%). Generally, the total number of met needs remained quite stable, but unmet needs decreased significantly over time, according to patients as well as to clinicians. Sensitivity to change of unmet needs is quite high: about two third of all unmet needs made a transition to no or met need, and more than half of all unmet needs at follow-up were new. Agreement between patient and clinician on unmet needs at baseline as well as follow-up was rather low, without any indication of a specific treatment effect.

Conclusions: Individual unmet needs appear to be quite sensitive to change over time but as yet less suitable as outcome criterion of treatment or specific interventions. 
Keywords: need for care, schizophrenia, routine outcome assessment, community mental health care 


\section{Introduction}

Generally, patients in community care have on average four to eight needs for care - as measured with the Camberwell Assessment of Need (CAN) or the Needs for Care Assessment (NCA) -, a number which appears to be rather unrelated to gender, age or education but does appear to be related to number of symptoms, diagnosis (e.g. higher in schizophrenia), and treatment setting (higher in inpatient care or among homeless people; [30,31]. Prevalence on total number of needs, met as well as unmet, appears to be quite stable on the population level, while any change (i.e. mostly a slight decrease at follow-up) seems hardly linked to number or kind of interventions $[6,8,15,23,29]$; although with some exception, see Salize et al [24]. One out of two to four needs appears to be unmet, in particular in the areas of psychological distress, daytime activities, social contacts, and psychotic symptoms. Prevalence of unmet needs seems to be related to the system of mental health care and to socioeconomic circumstances as well: the less integrated and continuous the care and the poorer the life situation, the more unmet needs. Many needs are also unmet in community-oriented settings with links to primary care, affecting at least 25$50 \%$ of the patient population. Unmet needs are a strong predictor of quality of life [26]. Recently, it was demonstrated that high levels of (met) need also predict (changes in) care consumption, in particular more inpatient care [2], while unmet needs seem to be unrelated to subsequent care.

It can be argued that mental health interventions should demonstrate an effect on patients' functioning as well as on their needs, in particular on unmet needs. Some studies have suggested that standardised needs assessment might improve outcome in terms of less unmet needs and ameliorization of symptoms and functioning [10,17] while recently Priebe et al [22] demonstrated such an effect more conclusively in an RCT on a novel mental 
health service intervention. However, methodological issues have to be taken into account. For example, the perspective of the beholder is important, as discrepancies between the patient and professional are substantial in terms of the number as well as the type of need $[5,9,27,28]$; also this study]. Further, most authors compare summary scores of total number of met and unmet needs, while Wennström and Wiesel [29] argue that this might be misleading by concealing changes on an individual need level. They demonstrate that while no change over a period of six years occurred in summary scores of the Camberwell Assessment of Needs (CAN), significant changes in need status on nearly all items were found and mostly in the favorable direction: remaining needs were more often met than not and many patients in need of care or support in 1997 appeared to be managing on their own without problems in 2003. The same phenomenon was found in a Dutch study [15] among 109 schizophrenia patients with a follow-up of 18 months. The persistence or stability of unmet needs seemed rather low; most (patient rated) unmet needs disappeared, while only those relating to daytime activities, psychological distress, and company were relatively stable in about $50 \%$ of the cases.

This raises the question of whether unmet needs could be used as an outcome criterion of the effectiveness of interventions in mental health care. We seek an answer to this question by investigating in detail the persistence or sensitivity to change of individual unmet needs over a one-year period, the incidence of new unmet needs at follow-up, and the concordance between patient rated needs and clinician rated needs, in the context of a novel mental health service intervention.

\section{Settings and design}

The present study was part of the DIALOG study, a cluster randomised controlled trial of a new intervention to improve communication between patient and clinician which was 
conducted in community psychiatric services in Granada (Spain), Groningen (The Netherlands), London (United Kingdom), Lund (Sweden), Mannheim (Germany), and Zurich (Switzerland) covering urban and mixed urban-rural areas. This novel intervention structures communication between patients and clinicians in routine meetings by means of a regular, two-monthly assessment of needs in 8 areas (mental health, physical health, job situation, accommodation, leisure activities, friendships, relationship with family/partner, and personal safety) with the support of a computer mediated technology (the so-called DIALOG intervention; [22]. The intervention had a small, but positive significant effect on the prevalence of self-reported unmet needs (effect size .22), on subjective quality of life (effect size .20), and on treatment satisfaction of the patients (effect size .28)

In this paper we focus on data from community mental health care teams in four centres only (Groningen, Lund, Mannheim, and Zurich) because of the availability of a need assessment by the patient as well as by the clinician. In all centres multidisciplinary teams provided comprehensive care programmes for people with severe and enduring mental illnesses. They operated a key worker system in which every patient had a designated clinician working within a team but with lead responsibility for care co-ordination and delivery.

Eligibility criteria for participating clinicians were a professional qualification in mental health and/or a minimum of one-year professional experience in an outpatient setting and an active caseload as key worker. Inclusion criteria for patients were: living in the community (not 24 hour supported accommodation); treatment by a community mental health care teams at least three months; capable of giving informed consent; having sufficient knowledge of the language of the host country; having a primary diagnosis of schizophrenia or related psychotic disorder (ICD-10 = F20-F29); having an age between 18 and 65 years; having at least one meeting with their key worker every two months with the 
expectation that they would continue with the service for the next 12 months; and having no severe organic psychiatric illness or primary substance abuse.

\section{Measurement}

Needs for care were measured on the Camberwell Assessment of Need Short Appraisal Schedule (CANSAS, [25]), which assesses health and social needs across 22 domains. For each domain it distinguishes between 'no need', 'met need', and 'unmet need'. Research assistants interviewed both the patient and his/her key worker for self reported needs and clinician rated needs in four centres (Groningen, Lund, Mannheim, and Zurich). Sociodemographic and clinical characteristics of patients were collected at baseline. The psychiatric diagnosis was obtained through a standardised and computer-based method using operationalised criteria (OPCRIT, [14]) and psychopathology was measured by means of the Positive and Negative Syndrome Scale (PANSS, [7]). Measures of patients' quality of life (MANSA, Priebe [21]), treatment satisfaction (CSQ, [16]) and clinicians' job satisfaction [19] were also used. Researchers received training in all rating procedures and achieved good inter-rater reliability using videotaped interviews for PANSS (Cohen's kappa $=0.71)$ and case vignettes for CANSAS (Cohen's kappa $=0.90)$.

\section{Statistical analysis}

Descriptive statistics are presented with frequency and percentage distributions for categorical data and means and standard deviations for continuous data. Correlation between baseline and follow-up was calculated by means of Rho for sumscores and the agreement between patient and clinician ratings on individual need items by means of Cohen's kappa (unweighted). Change in individual unmet needs was tested by means of chi-square in 2x2 tables. All data were analysed using SPSS-14.0 for Windows. 


\section{Results}

The four centres included 102 clinicians (49 in the DIALOG condition and 53 in the Care as Usual condition) with a key worker role and a total of 320 patients (174 in DIALOG and 146 in Cau). At follow-up 294 patients (92\%) had baseline as well as follow-up ratings on needs for care, while clinician rated needs were available for 302 patients (94\%) at both occasions. Baseline characteristics, both socio-demographic and clinical, of patients and clinicians are shown in Table 1.

Insert Table 1 here (baseline characteristics)

Most patients were male (67\%) and single (70\%), while nearly half (43\%) had paid or sheltered work. The duration of illness was about 18 years with nearly seven admissions. Patients were mixed to mostly satisfied with their life and with their treatment. Patients were treated by slightly older and mostly female clinicians $(67 \%$ of them were psychiatric nurses or social workers), who had an average caseload of about 20 patients) were quite satisfied with their job.

\section{Prevalence of needs (sum indices)}

Patient rated needs remained quite stable over time but unmet needs decreased significantly from 2.0 to 1.6 , and the proportion of patients without unmet needs increased from $34.0 \%$ to $39.1 \%$. The clinician rated needs also remained stable on a slightly higher level (on average 8.0 ) with a significant decrease of unmet needs over time from 2.3 to 1.7 , as well as an increase of the proportion of patients without unmet needs (from $31.3 \%$ to 39.3 ). Thus, unmet needs generally decreased, in absolute as well as relative numbers, both for 
patient rated as well as clinician rated needs. Correlation between baseline and follow-up need ratings was modest (all below .60) suggesting quite some variability in numbers per patient.

Insert table 2 (prevalence of needs) about here

By far ( $>90 \%)$, the most prevalent need was related to psychotic symptoms (mostly met), followed in about $40 \%$ of the cases by needs in the area of accommodation, looking after home, daytime activities, physical health, information, distress, company, intimate relationships, and money. The highest prevalence of unmet needs was for intimate relationships, company, psychological distress, daytime activities, and physical health (15$28 \%$ ); the relative difference between patient and clinician rated needs in this aspect was relatively small (data on individual need items not shown in table).

\section{Sensitivity to change of individual unmet needs at follow-up}

Of all patient rated baseline unmet needs ( $\mathrm{N}=584$; see table 3 ) $37.0 \%$ persisted after one year; in particular in the domains of psychotic symptoms, company, intimate relations, and transport (around 50\%). This was the case for $34.9 \%$ of clinician rated unmet needs $(\mathrm{N}=680)$; in particular in the domains daytime activities, psychotic symptoms, alcohol, drugs, intimate relations, sexual expression, and money (also around 40-50\%). Thus, most unmet needs, according to both perspectives, made a transition to no need or met need.

Table 3 about here 
Looking back retrospectively, more than half of the unmet needs at follow-up were new (54.5\% for patient rated and $51.9 \%$ for clinician rated needs). Substantial proportions (30.1\% and $23.1 \%$ respectively) were rated as no need at baseline. Generally, unmet needs in the domains of intimate relationships, sexual expression, company, day-time activities, physical health, and psychological distress were rated by boths rather frequently as new. Also, substantial proportions of patients without an unmet need at baseline had at least one unmet need at follow-up (31\% according to patients and 38\% according to clinicians). The same applies to patients with at least one unmet need at baseline and none one year later ( $24 \%$ according to patients and $29 \%$ according to clinicians). Change in these proportions was not related to the treatment condition.

Table 4 about here

Agreement (Cohen's Kappa) between the patient and clinician on individual needs at baseline was on average .27 , which raised to .30 at follow-up. This actually did not reflect a better agreement on unmet needs; on the contrary, the average proportion of agreement of patients with their clinicians on all unmet needs dropped from $40 \%$ to $30 \%$, and the same occurred with the agreement of the clinicians with the patients on unmet needs $(33 \%$ at baseline to $29 \%$ at follow-up). One could argue whether agreement between patient and clinician on unmet needs at baseline would increase the chance on a met or no need later on, and whether the treatment condition would made a difference (the DIALOG condition would be expected to do better). However, it appeared that in those cases in which patient and clinician agreed on unmet need status at baseline (on average $16 \%$, range from $0 \%$ to $40 \%$, in particular more frequently with respect to daytime activities, physical health, psychotic symptoms, psychological distress, company, intimate relationships, and sexual 
expression), no association with a met need status at follow-up showed up, and without a differential effect of treatment condition.

Table 5 about here

\section{Discussion}

This one-year follow-up study of prevalence of patient rated as well as clinician rated individual needs for care among 320 patients and their 98 key workers in community health centers in four countries showed a rather stable number of met needs but a statistically significantly decreasing number of unmet needs and an increasing number of patients without any unmet need. Most unmet needs, nearly two thirds, according to both patients and clinicians, were met or had disappeared at the time of follow-up: only four patient rated unmet needs of psychotic symptoms, company, intimate relations, and transport were relatively persistent (around 50\%), while for clinician rated unmet needs this was the case for daytime activities, psychotic symptoms, alcohol, drugs, intimate relations, sexual expression, and money (40-50\%). The incidence of unmet needs over one year was relatively high considering the chronic illness duration of about 18 years and the existence of multiple problems: $52-55 \%$ of the follow-up unmet needs were new. Finally, the concordance between met and unmet needs at baseline and follow-up and the agreement between patients and their clinicians at both occasions were low and virtually absent. There was no indication that treatment condition (usual care with or without the novel intervention DIALOG) had a discernible influence on the reduction or prevention of individual unmet needs. Latter outcome seems somewhat discrepant with the result of the reported overall effect of the DIALOG intervention on the reduction of unmet needs which 
-using the sum index- is indeed not statistically significant anymore $(P=.07)$, probably due to the reduced power (from $\mathrm{N}=502$ to 320 ) with the exclusion of two centres with the greatest effect sizes (Granada and London). However, the focus of this paper is more on individual needs.

The strength of this study is a high inclusion rate of people with long term problems in community mental health care settings with a low number lost to follow-up (6-8\%) and only a few changes of clinicians affecting a low number of patients [22]. One limitation is the use of exclusion criteria for the sake of the clinical trial regarding diagnosis (only schizophrenia or related psychotic disorders), physical handicaps or organic illness, age, or insufficient contact with care coordinator, which might restrict generalization to the whole patient population in community care. The post hoc nature of the present analysis allows for tentative conclusions only.

The agreement between patient and clinician was rather small, although both were interviewed by the same investigators who were properly trained and monitored. The interrater reliability of CAN is well established $[4,13,18]$; this study on case vignettes: Kappa $.90)$ and found to be good to excellent, at least on the level of summary measures with a slight fall-off for unmet needs, while the test-retest and the inter-rater reliability with regard to individual items of needs appeared to be much less. The agreement between patient and staff ratings of needs generally is quite moderate and particularly insufficient as to individual items of unmet needs [28] (also this study: proportion between 29 and 40\%; Kappa between .14 - .30). An observation is that the follow-up ratings of needs have been made by the investigators without explicitly taking into account the baseline measurement. The assessment of the status of unmet needs could therefore be strengthened by additional 
probing and checking of the reasons why that status has changed over time in the eye of the beholder. Another consideration, based on the study of Drukker et al [2], is to assess needs not by an independent researcher but by both parties involved together; this may yield ratings which better reflect the clinical relevance of a problem and the validity of its need status (met or unmet) over time (see also Macpherson et al [11] ). It is possibly a limitation in our study that the need assessment was research oriented and not used as a clinical tool to guide the intervention.

The prevalence rate of met and unmet needs in our study is in line with earlier research including the (significant) tendency towards lower numbers at follow-up [8,30]. Overall these findings are more or less consistent with the CAN literature. However, our data suggest an overall high sensitivity to change and a high incidence of individual unmet needs among patients with chronic psychiatric and social problems, no matter whether these were rated by the patient or the clinician. This is rather surprising and possibly an underestimated phenomenon. Wennström and Wiesel [29] observed over a period of six years that the mean number of (unmet) needs did not change much (about 6.3 for total and 1.5 for unmet needs), most ( $82 \%$ ) needs in 1997 were (still) met or had disappeared in 2003 and more than $70 \%$ of needs occurring after baseline were met at follow-up. They see this as an indication of effective care that successfully meets the health needs of the patients and argued that summary indices of needs are not a valid outcome measure in routine mental health care because they conceal important changes over time on the individual level of needs. The same variability of self-perceived unmet needs was also found in a Dutch study [15] among 109 schizophrenia patients with a follow-up of 18 months; most unmet needs disappeared, while only those relating to day-time activities, psychological distress, and company were relatively stable (about $50 \%$ of the cases). Transitions from 
unmet need to no or met need maybe due to various sources, such as general or specific interventions from mental health services, psychological adjustment processes, life changes, time effect, etc.

Do our findings (and of others) provide indications that usual care includes such an effective rehabilitative effort that unmet needs are likely to disappear? Can it be argued that community mental health care in western industrialised countries is so advanced that we could expect such changes in unmet needs over time? On the one hand, Fakhoury \& Priebe [3] criticised community mental health care and urged toward establishing better practice to support continuity of care and guided sheltered living. On the other hand Kovess-Masféty et al [8] demonstrated in their follow-up study (with another instrument, the Needs for Care Assessment, [1]) among 391 in-, out-, and day-patients with schizophrenia in six European centres that the number of proposed interventions was not related to need status but that the availability of community based treatment (outpatient and rehabilitation services) seems indeed to be related to (less) unmet needs. And Kallert and Leisse [6] showed a trend towards rating unmet needs (e.g. communication, slowness, and underactivity) as not meetable over time. This option of rating a need as no meetable is not available in the CANSAS.

Thus so far much evidence of the effectiveness of regular community mental health care is still lacking and the concept of unmet needs as a firm outcome criterion is probably premature. There remains a discrepancy between a stable chronic patient population with relatively high numbers of unmet needs - which not unexpectedly are difficult to meet on the one hand and the disappearance of most unmet needs in a relatively very short time on the other. Could it be partly ascribed to conceptual issues? Priebe et al. [20] argue that the concept of need inappropriately simplifies the actual process of clinical decision making. They propose a way-out by clearly identifying problems, specifying goals, and choosing 
interventions of which the outcomes should be regularly be monitored. This might, for example, be better guaranteed by a more complex instrument like the Needs of Care Assessment $[1,12]$, which may partly solve these conceptual issues but carries with it other problems of training, implementation, rating, and the perspective of one beholder (the clinician).

Our retrospective secondary analysis should be followed by prospective quantitative investigations using repeated measures to study the association between intervention and consequent impact on need status in specific domains, to assess whether the CAN is indeed sensitive to change, a true change or due to measurement error. Also more qualitative domain-specific assessment of change is worthwhile in order to better understand what it means when an unmet need changes or emerges, and to establish the domains which change due to health service intervention compared with the domains which change for other reasons. 


\section{APPENDIX}

The Mediating Community Care Group includes the following: Granada: Marta Ribes

Leyva, Maria F Soriano Peña, Beatriz Arroyo de Domingo. Groningen: Kerstin Wolters, Aukelien Mulder, Jappie Tiersma. London: Rakhee Haque. Lund: Tommy Björkman.

Mannheim: Marita Reichenbacher, Anette Axt. Zurich: Patric Meyer, Minka Burgi.

We are indebted to the clinicians and patients who took part in the Mediating Community

Care study, to Dr Michael Dewey for statistical advice, and to Dr Patrick Healey and Greg

Mills for software development and technical support. 


\section{Reference List}

1. Brewin CR, Wing JK, Mangen SP, Brugha TS, MacCarthy B (1987) Principles and practice of measuring needs in the long-term mentally ill: the MRC needs for care assessment. Psychol Med 17:971-981

2. Drukker M, Bak M, Driessen G, Van OJ, Delespaul PA (2007) Can the "Camberwell Assessment of Need" predict changes in care consumption? Tijdschr Psychiatr $49: 305-314$

3. Fakhoury WK, Priebe S (2002) The process of deinstitutionalization: an international overview. Curr Opin Psychiatry 15:187-192

4. Hansson L, Bjorkman T, Svensson B (1995) The assessment of needs in psychiatric patients. Interrater reliability of the Swedish version of the Camberwell Assessment of Needs instrument and results from a cross-sectional study. Acta Psychiatr Scand $92: 285-293$

5. Hansson L, Vinding HR, Mackeprang T, Sourander A, Werdelin G, Bengtsson-Tops A, Bjarnason O, Dybbro J, Nilsson L, Sandlund M, Sorgaard K, Middelboe T (2001) Comparison of key worker and patient assessment of needs in schizophrenic patients living in the community: a Nordic multicentre study. Acta Psychiatr Scand 103:45-51

6. Kallert TW, Leisse M (2001) Schizophrenic patients' normative needs for community-based psychiatric care: an evaluative study throughout the year following hospital release in the Dresden region. Soc Psychiatry Psychiatr Epidemiol 36:1-12

7. Kay SR, Fiszbein A, Opler LA (1987) The positive and negative syndrome scale (PANSS) for schizophrenia. Schizophr Bull 13:261-276

8. Kovess-Masféty V, Wiersma D, Xavier M, Caldas de Almeida JM, Carta MG, Dubuis J, Lacalmontie E, Pellet J, Roelandt JL, Torres-Gonzalez F, Moreno Kustner 
B, Walsh D (2006) Needs for care among patients with schizophrenia in six European countries: a one-year follow-up study. Clin Pract Epidemol Ment Health 2:22

9. Lasalvia A, Ruggeri M, Mazzi MA, Dall'Agnola RB (2000) The perception of needs for care in staff and patients in community-based mental health services. The SouthVerona Outcome Project 3. Acta Psychiatr Scand 102:366-375

10. Lockwood A, Marshall M (1999) Can a standardized needs assessment be used to improve the care of people with severe mental disorders? A pilot study of 'needs feedback'. J Adv Nurs 30:1408-1415

11. MacPherson R, Gregory N, Slade M, Foy C (2007) Factors associated with changing patient needs in an assertive outreach team. Int J Soc Psychiatry 53:389-396

12. Marshall M, Hogg LI, Gath DH, Lockwood A (1995) The Cardinal Needs Schedule-a modified version of the MRC Needs for Care Assessment Schedule. Psychol Med $25: 605-617$

13. McCrone P, Leese M, Thornicroft G, Schene AH, Knudsen HC, Vazquez-Barquero JL, Lasalvia A, Padfield S, White IR, Griffiths G (2000) Reliability of the Camberwell Assessment of Need--European Version. EPSILON Study 6. European Psychiatric Services: Inputs Linked to Outcome Domains and Needs. Br J Psychiatry Suppl 177:s34-s40

14. McGuffin P, Farmer A, Harvey I (1991) A polydiagnostic application of operational criteria in studies of psychotic illness. Development and reliability of the OPCRIT system. Arch Gen Psychiatry 48:764-770

15. Meijer CJ, Koeter MWJ, Schene AH (2005) Temporal stability of needs for care and the relation with quality of life: a longitudinal study among patients with schizophrenia. In: Meijer CJ ed. Quality of life and needs for care of patients with schizophrenia (Thesis). University of Amsterdam, Amsterdam, pp. 60-72 
16. Nguyen TD, Attkisson CC, Stegner BL (1983) Assessment of patient satisfaction: development and refinement of a service evaluation questionnaire. Eval Program Plann 6:299-313

17. O'Leary D, Webb M (1996) The need for care assessment - A longitudinal approach. Psychiatr Bull 20:134-136

18. Phelan M, Slade M, Thornicroft G, Dunn G, Holloway F, Wykes T, Strathdee G, Loftus L, McCrone P, Hayward P (1995) The Camberwell Assessment of Need: the validity and reliability of an instrument to assess the needs of people with severe mental illness. Br J Psychiatry 167:589-595

19. Priebe S, Fakhoury WK, Hoffmann K, Powell RA (2005) Morale and job perception of community mental health professionals in Berlin and London. Soc Psychiatry Psychiatr Epidemiol 40:223-232

20. Priebe S, Huxley P, Burns T (1999) Who needs needs? European Psychiatry 14:186188

21. Priebe S, Huxley P, Knight S, Evans S (1999) Application and results of the Manchester Short Assessment of Quality of Life (MANSA). Int J Soc Psychiatry $45: 7-12$

22. Priebe S, Mccabe R, Bullenkamp J, Hansson L, Lauber C, Martinez-Leal R, Rössler W, Salize HJ, Svensson B, Torres-Gonzales F, Brink van den RHS, Wiersma D, Wright DJ (2007) Structured patient-clinician communication and one-year outcome in community mental health care: A cluster randomised controlled trial. $\mathrm{Br} \mathrm{J}$ Psychiatry in press:

23. Ruggeri M, Leese M, Slade M, Bonizzato P, Fontecedro L, Tansella M (2004) Demographic, clinical, social and service variables associated with higher needs for 
care in community psychiatric service patients. The South Verona Outcome Project 8. Soc Psychiatry Psychiatr Epidemiol 39:60-68

24. Salize HJ, Kustner BM, Torres-Gonzalez F, Reinhard I, Estevez JF, Rossler W (1999) Needs for care and effectiveness of mental health care provision for schizophrenic patients in two European regions: a comparison between Granada (Spain) and Mannheim (Germany). Acta Psychiatr Scand 100:328-334

25. Slade M, Beck A, Bindman J, Thornicroft G, Wright S (1999) Routine clinical outcome measures for patients with severe mental illness: CANSAS and HoNOS. Br J Psychiatry 174:404-408

26. Slade M, Leese M, Taylor R, Thornicroft G (1999) The association between needs and quality of life in an epidemiologically representative sample of people with psychosis. Acta Psychiatr Scand 100:149-157

27. Slade M, Phelan M, Thornicroft G (1998) A comparison of needs assessed by staff and by an epidemiologically representative sample of patients with psychosis. Psychol Med 28:543-550

28. Slade M, Phelan M, Thornicroft G, Parkman S (1996) The Camberwell Assessment of Need (CAN): comparison of assessments by staff and patients of the needs of the severely mentally ill. Soc Psychiatry Psychiatr Epidemiol 31:109-113

29. Wennström E, Wiesel FA (2006) The Camberwell assessment of need as an outcome measure in routine mental health care. Soc Psychiatry Psychiatr Epidemiol 41:728733

30. Wiersma D (2006) Needs of people with severe mental illness. Acta Psychiatr Scand Suppl 113:115-119 
31. Wiersma D, Giel R, Jong de A, Nienhuis FJ, Slooff CJ (1996) Assessment of the need for care 15 years after onset of a Dutch cohort of patients with schizophrenia, and an international comparison. Soc Psychiatry Psychiatr Epidemiol 31:114-121 
Table 1. Baseline Sociodemographic Characteristics of Patients and their Clinicians, means (SD) and proportions (\%).

Patients ( $\mathbf{N}=\mathbf{3 2 0}$ )

\begin{tabular}{|c|c|}
\hline Mean age (yr) & $42.8(10.8)$ \\
\hline Male & $67.2 \%$ \\
\hline Marital status (single) & $70.3 \%$ \\
\hline Employed (incl. Sheltered work) & $42.5 \%$ \\
\hline Unemployed & $27.5 \%$ \\
\hline Other & $30.0 \%$ \\
\hline \multicolumn{2}{|l|}{ Diagnosis } \\
\hline Undifferentiated schizophrenia & $39.1 \%$ \\
\hline Paranoid schizophrenia & $24.1 \%$ \\
\hline Other (schizo-affective, delusional) & $17.4 \%$ \\
\hline Other non-organic psychosis & $19.4 \%$ \\
\hline Mean length of illness (yr) & $17.8(9.8)$ \\
\hline Mean number hospital admissions & $6.7(8.5)$ \\
\hline Quality of Life & $4.8(0.9)$ \\
\hline Satisfaction with treatment & $25.4(4.0)$ \\
\hline \multicolumn{2}{|l|}{ Symptomatology (PANSS) } \\
\hline Positive subscale & $14.7(5.8)$ \\
\hline Negative subscale & $16.6(6.7)$ \\
\hline General subscale & $32.6(9.6)$ \\
\hline \multicolumn{2}{|l|}{ Clinicians ( $N=98)$} \\
\hline Mean age (yr) & $45.0(8.9)$ \\
\hline Male & $37.3 \%$ \\
\hline \multicolumn{2}{|l|}{ Profession } \\
\hline Psychiatric nurse & $45.9 \%$ \\
\hline Social worker & $21.4 \%$ \\
\hline Psychiatrist & $10.2 \%$ \\
\hline Psychologist & $5.1 \%$ \\
\hline Other & $17.3 \%$ \\
\hline Mean length of service (yr) & $14.3(8.7)$ \\
\hline Average caseload & $21.3(13.3)$ \\
\hline Job satisfaction $[\mathrm{N}=71]$ & $75.0(6.9)$ \\
\hline
\end{tabular}


Table 2. Prevalence of patient rated and clinician rated needs for care (sum indices) at baseline and 1-year follow-up, means and standard deviations (SD).

\begin{tabular}{|c|c|c|c|c|c|}
\hline $\begin{array}{l}\text { Patient rated } \\
\text { needs }(N=294)\end{array}$ & $\begin{array}{c}\text { Baseline } \\
\text { (SD) }\end{array}$ & $\begin{array}{c}\text { Follow-up } \\
\text { (SD) }\end{array}$ & $\begin{array}{c}P \\
(\text { t-test/chi- } \\
\text { square })\end{array}$ & $\begin{array}{l}\text { Correlation } \\
\qquad(P)\end{array}$ & $\begin{array}{c}\text { Difference } \\
\text { (SD) }\end{array}$ \\
\hline Total Needs & $6.8(3.1)$ & $6.6(2.9)$ & .41 & $.44(.000)$ & $.15(3.2)$ \\
\hline Met Needs & $4.8(2.7)$ & $5.0(2.8)$ & .22 & $.37(.000)$ & $-.22(3.1)$ \\
\hline Unmet Needs & $2.0(2.8)$ & $1.6(1.9)$ & .001 & $.59(.000)$ & $.37(1.9)$ \\
\hline $\begin{array}{r}\text { Proportion of } \\
\text { patients } \\
\text { without unmet } \\
\text { needs }\end{array}$ & $34.0 \%$ & $39.1 \%$ & .000 & & \\
\hline $\begin{array}{l}\text { Clinician rated } \\
\text { needs }(\mathrm{N}=302)\end{array}$ & $\begin{array}{c}\text { Baseline } \\
\text { (SD) }\end{array}$ & $\begin{array}{c}\text { Follow-up } \\
\text { (SD) }\end{array}$ & $\begin{array}{c}P \\
(\text { t-test/chi- } \\
\text { square })\end{array}$ & $\begin{array}{c}\text { Correlation } \\
\qquad(P)\end{array}$ & $\begin{array}{c}\text { Difference } \\
\text { (SD) }\end{array}$ \\
\hline Total Needs & $8.3(3.7)$ & $8.0(3.7)$ & .06 & $.59(.000)$ & $.37(3.4)$ \\
\hline Met Needs & $6.0(3.2)$ & $6.3(3.4)$ & .16 & $.49(.000)$ & $-.27(3.3)$ \\
\hline Unmet Needs & $2.3(2.6)$ & $1.7(2.1)$ & .000 & $.46(.000)$ & $.63(2.5)$ \\
\hline $\begin{array}{r}\text { Proportion of } \\
\text { patients } \\
\text { without unmet } \\
\text { needs }\end{array}$ & $31.3 \%$ & $39.3 \%$ & .000 & & \\
\hline
\end{tabular}


Table 3. Sensitivity to change of baseline Individual Unmet Needs at 1-yr follow-up

Status of Individual Needs at 1 yr follow-up

\begin{tabular}{rcccc}
\hline $\begin{array}{r}\text { Unmet Needs } \\
\text { at baseline: }\end{array}$ & No Need & Met Need & Unmet Need & Total \\
Patient rated & $209(35.8 \%)$ & $159(27.2 \%)$ & $216(37.0 \%)$ & $\mathbf{5 8 4}(\mathbf{1 0 0 \%})$ \\
Clinician rated & $199(29.3 \%)$ & $244(35.9 \%)$ & $237(34.9 \%)$ & $\mathbf{6 8 0}(\mathbf{1 0 0 \%})$ \\
\hline
\end{tabular}


Table 4. Baseline Status of Individual Unmet Needs at 1-year follow-up

\begin{tabular}{|c|c|c|}
\hline $\begin{array}{l}\text { Need Status } \\
\text { at baseline: }\end{array}$ & $\begin{array}{l}\text { Patient rated Unmet } \\
\text { Needs at follow-up }\end{array}$ & $\begin{array}{l}\text { Clinician rated Unmet } \\
\text { Needs at follow-up }\end{array}$ \\
\hline No need & $143(30.1 \%)$ & $114(23.1 \%)$ \\
\hline Met need & $116(24.4 \%)$ & $143(28.9 \%)$ \\
\hline Unmet need & $216 \quad(45.5 \%)$ & $237(48.0 \%)$ \\
\hline Total & $475(100 \%)$ & $494(100 \%)$ \\
\hline
\end{tabular}


Table 5. Agreement between Patient rated and Clinician rated Needs, at baseline and 1 year follow-up (Spearman correlation and Cohen's Kappa)

\section{Correlation}

Baseline ( $\mathbf{N}=317)$

$\begin{array}{rr}\text { Sum index of Total Needs } & .36 \\ \text { Sum index of Unmet Needs } & .46\end{array}$

Average over Individual Unmet Needs (3 categories) .34 (Rho) or .27 (Kappa)

Follow-up $(\mathrm{N}=\mathbf{2 8 9})$

$\begin{array}{rc}\text { Sum index of Total Needs } & .46 \\ \text { Sum index of Unmet Needs } & .34 \\ \text { Unmet Needs (3 categories) } & .34 \text { (Rho) or .30 (Kappa) }\end{array}$

Baseline: Mean proportion agreement on individual needs of

$$
\begin{array}{ll}
\text { patient with clinician } & 40 \% \\
\text { clinician with patient } & 33 \%
\end{array}
$$

Follow-up: Mean proportion agreement on individual needs of

$\begin{array}{ll}\text { patient with clinician } & 30 \% \\ \text { clinician with patient } & 29 \%\end{array}$


1

2

3

7 August 2008 resubmitted to Social Psychiatry and Psychiatric Epidemiology

\begin{abstract}
: $\quad 296$
Word count: 3552

Tables: $\quad 5$
\end{abstract}

\title{
Individual Unmet Needs for Care: are they sensitive as outcome criterion for the effectiveness of mental health services interventions?
}

\section{Short title: Unmet Needs for Care as outcome criterion}

Durk Wiersma ${ }^{1}$, Rob van den Brink ${ }^{1}$, Kerstin Wolters ${ }^{1}$, Rosemarie McCabe ${ }^{2}$, Jens Bullenkamp ${ }^{5}$, Lars Hansson ${ }^{4}$, Christoph Lauber ${ }^{6}$, Rafael Martinez-Leal ${ }^{3}$, Wulf Rössler ${ }^{6}$, Hans Salize ${ }^{5}$, Bengt Svensson ${ }^{4}$, Francisco Torres-Gonzales ${ }^{3}$, Donna J. Wright ${ }^{2}$, Stefan Priebe $^{2}$

From the ${ }^{1}$ University Medical Center Groningen, Department of Psychiatry, University of Groningen, The Netherlands; the ${ }^{2}$ Unit for Social and Community Psychiatry, Queen Mary University of London, UK; the ${ }^{3}$ Department of Psychiatry, University of Granada, Granada, Spain; ${ }^{4}$ University of Lund, Lund, Sweden; ${ }^{5}$ Central Institute for Mental Health, Mannheim, Germany; the ${ }^{6}$ Psychiatric University Hospital, Liverpool, UK

Correspondence to Dr. D.Wiersma at the University Medical Center Groningen, Department of Psychiatry, University of Groningen, P.O.Box 30.001, 9700 RB Groningen, The Netherlands

Tel +31503613839

Fax +31503619722

durk.wiersma@med.umcg.nl

Funding/Support: The study was funded by the Research Directorate of the European Commission within the Framework Programme 5 (QLG5-CT-2002-01938). 


\section{Abstract}

Background: Mental health interventions should demonstrate an effect on patients' functioning as well as his/her needs, in particular on unmet needs whose assessment depends on the perspective of either the patient or the clinician. However, individual met and unmet needs appear to change over time, qualitatively and quantitatively, raising questions about their sensitivity to change and about the association between level of needs and treatment.

Methods: Data on baseline and follow-up need assessment in community mental health services in four European countries in the context of a cluster randomised trial on a novel mental health service intervention were used, which involved 102 clinicians with key worker roles and 320 patients with schizophrenia or related psychotic disorders. Need assessment was performed with the Camberwell Assessment of Needs Short Appraisal Schedule (CANSAS) among patients as well as clinicians. Focus is the sensitivity to change in unmet needs over time as well as the concordance between patient and clinician ratings and their relationship with treatment condition.

Results: At follow-up 294 patients (92\%) had a full need assessment, while clinician rated needs were available for 302 patients (94\%). Generally, the total number of met needs remained quite stable, but unmet needs decreased significantly over time, according to patients as well as to clinicians. Sensitivity to change of unmet needs is quite high: about two third of all unmet needs made a transition to no or met need, and more than half of all unmet needs at follow-up were new. Agreement between patient and clinician on unmet needs at baseline as well as follow-up was rather low, without any indication of a specific treatment effect.

Conclusions: Individual unmet needs appear to be quite sensitive to change over time but as yet less suitable as outcome criterion of treatment or specific interventions. 
Keywords: need for care, schizophrenia, routine outcome assessment, community mental health care 


\section{Introduction}

Generally, patients in community care have on average four to eight needs for care - as measured with the Camberwell Assessment of Need (CAN) or the Needs for Care Assessment (NCA) - , a number which appears to be rather unrelated to gender, age or education but does appear to be related to number of symptoms, diagnosis (e.g. higher in schizophrenia), and treatment setting (higher in inpatient care or among homeless people; $[34,35]$. Prevalence on total number of needs, met as well as unmet, appears to be quite stable on the population level, while any change (i.e. mostly a slight decrease at follow-up) seems hardly linked to number or kind of interventions $[10,12,19,27,33]$; although with some exception, see Salize et al [28]. One out of two to four needs appears to be unmet, in particular in the areas of psychological distress, daytime activities, social contacts, and psychotic symptoms. Prevalence of unmet needs seems to be related to the system of mental health care and to socioeconomic circumstances as well: the less integrated and continuous the care and the poorer the life situation, the more unmet needs. Many needs are also unmet in community oriented settings with links to primary care, affecting at least 25$50 \%$ of the patient population. Unmet needs are a strong predictor of quality of life $[9,30]$. Recently, it was demonstrated that high levels of (met) need also predict (changes in) care consumption, in particular more inpatient care [4], while unmet needs seem to be unrelated to subsequent care.

It can be argued that mental health interventions should demonstrate an effect on patients' functioning as well as on their needs, in particular on unmet needs. Some studies have suggested that standardised needs assessment might improve outcome in terms of less

unmet needs and ameliorization of symptoms and functioning [14,21] while recently Priebe et al [26] demonstrated such an effect more conclusively in an RCT on a novel mental health service intervention. However, methodological issues have to be taken into account. 
For example, the perspective of the beholder is important, as discrepancies between the patient and professional are substantial in terms of the number as well as the type of need $[8,13,31,32]$; also this study]. Further, most authors compare summary scores of total number of met and unmet needs, while Wennström and Wiesel [33] argue that this might be misleading by concealing changes on an individual need level. They demonstrate that while no change over a period of six years occurred in summary scores of the Camberwell Assessment of Needs (CAN), significant changes in need status on nearly all items were found and mostly in the favorable direction: remaining needs were more often met than not and many patients in need of care or support in 1997 appeared to be managing on their own without problems in 2003. The same phenomenon was found in a Dutch study [19] among 109 schizophrenia patients with a follow-up of 18 months. The persistence or stability of unmet needs seemed rather low; most (patient rated) unmet needs disappeared, while only those relating to daytime activities, psychological distress, and company were relatively stable in about $50 \%$ of the cases.

This raises the question of whether unmet needs could be used as an outcome criterion of the effectiveness of interventions in mental health care. We seek an answer to this question by investigating in detail the persistence or sensitivity to change of individual unmet needs over a one-year period, the incidence of new unmet needs at follow-up, and the concordance between patient rated needs and clinician rated needs, in the context of a novel mental health service intervention.

\section{Settings and design}

The present study was part of the DIALOG study, a cluster randomised controlled trial of a new intervention to improve communication between patient and clinician which was conducted in community psychiatric services in Granada (Spain), Groningen (The 
Netherlands), London (United Kingdom), Lund (Sweden), Mannheim (Germany), and Zurich (Switzerland) covering urban and mixed urban-rural areas. This novel intervention structures communication between patients and clinicians in routine meetings by means of a regular, two-monthly assessment of needs in 8 areas (mental health, physical health, job situation, accommodation, leisure activities, friendships,, relationship with family/partner, and personal safety) with the support of a computer mediated technology (the so-called DIALOG intervention; [26]. The intervention had a small, but positive significant effect on the prevalence of self-reported unmet needs (effect size .22), on subjective quality of life (effect size .20), and on treatment satisfaction of the patients (effect size .28).

In this paper we focus on data from community mental health care teams in four centres only (Groningen, Lund, Mannheim, and Zurich) because of the availability of a need assessment by the patient as well as by the clinician. Logistical reasons and lack of research resources prevented such an assessment in Granada and London. In all centres multidisciplinary teams provided comprehensive care programmes for people with severe and enduring mental illnesses. They operated a key worker system in which every patient had a designated clinician working within a team but with lead responsibility for care coordination and delivery.

Eligibility criteria for participating clinicians were a professional qualification in mental health and/or a minimum of one-year professional experience in an outpatient setting and an active caseload as key worker. Inclusion criteria for patients were: living in the community (not 24 hour supported accommodation); treatment by a community mental health care teams at least three months; capable of giving informed consent; having sufficient knowledge of the language of the host country; having a primary diagnosis of schizophrenia or related psychotic disorder (ICD-10 = F20-F29); having an age between 18 and 65 years; having at least one meeting with their key worker every two months with the 
expectation that they would continue with the service for the next 12 months; and having no severe organic psychiatric illness or primary substance abuse.

\section{Measurement}

Needs for care were measured on the Camberwell Assessment of Need Short Appraisal Schedule (CANSAS, [29]), which assesses health and social needs across 22 domains. For each domain it distinguishes between 'no need', 'met need', and 'unmet need'. Research assistants interviewed both the patient and his/her key worker for self reported needs and clinician rated needs in four centres (Groningen, Lund, Mannheim, and Zurich). Sociodemographic and clinical characteristics of patients were collected at baseline. The psychiatric diagnosis was obtained through a standardised and computer-based method using operationalised criteria (OPCRIT, [18]) and psychopathology was measured by means of the Positive and Negative Syndrome Scale (PANSS, [11]). Measures of patients' quality of life (MANSA, [25]), treatment satisfaction (CSQ, [20]) and clinicians' job satisfaction [23] were also used. Researchers received training in all rating procedures and achieved good inter-rater reliability using videotaped interviews for PANSS (Cohen's kappa $=0.71)$ and case vignettes for CANSAS (Cohen's kappa $=0.90)$.

\section{Statistical analysis}

Descriptive statistics are presented with frequency and percentage distributions for categorical data and means and standard deviations for continuous data. Correlation between baseline and follow-up was calculated by means of Rho for sumscores and the agreement between patient and clinician ratings on individual need items by means of Cohen's kappa (unweighted). Change in individual unmet needs was tested by means of chi-square in 2x2 tables. All data were analysed using SPSS-14.0 for Windows. 


\section{Results}

The four centres included 102 clinicians (49 in the DIALOG condition and 53 in the Care as Usual condition) with a key worker role and a total of 320 patients (174 in DIALOG and 146 in Cau). At follow-up 294 patients (92\%) had baseline as well as follow-up ratings on needs for care, while clinician rated needs were available for 302 patients (94\%) at both occasions. Baseline characteristics, both socio-demographic and clinical, of patients and clinicians are shown in Table 1.

Insert Table 1 here (baseline characteristics)

Most patients were male (67\%) and single (70\%), while nearly half (43\%) had paid or sheltered work. The duration of illness was about 18 years with nearly seven admissions. Patients were mixed to mostly satisfied with their life and with their treatment. Patients were treated by slightly older and mostly female clinicians $(67 \%$ of them were psychiatric nurses or social workers), who had an average caseload of about 20 patients) were quite satisfied with their job.

\section{Prevalence of needs (sum indices)}

Patient rated needs remained quite stable over time but unmet needs decreased significantly from 2.0 to 1.6, and the proportion of patients without unmet needs increased from $34.0 \%$ to $39.1 \%$. The clinician rated needs also remained stable on a slightly higher level (on average 8.0) with a significant decrease of unmet needs over time from 2.3 to 1.7 , as well as an increase of the proportion of patients without unmet needs (from $31.3 \%$ to 39.3 ). Thus, unmet needs generally decreased, in absolute as well as relative numbers, both for 
patient rated as well as clinician rated needs. Correlation between baseline and follow-up need ratings was modest (all below .60) suggesting quite some variability in numbers per patient.

Insert table 2 (prevalence of needs) about here

By far ( $>90 \%)$, the most prevalent need was related to psychotic symptoms (mostly met), followed in about $40 \%$ of the cases by needs in the area of accommodation, looking after home, daytime activities, physical health, information, distress, company, intimate relationships, and money. The highest prevalence of unmet needs was for intimate relationships, company, psychological distress, daytime activities, and physical health (15$28 \%$ ); the relative difference between patient and clinician rated needs in this aspect was relatively small (data on individual need items not shown in table).

\section{Sensitivity to change of individual unmet needs at follow-up}

Of all patient rated baseline unmet needs ( $\mathrm{N}=584$; see table 3 ) $37.0 \%$ persisted after one year; in particular in the domains of psychotic symptoms, company, intimate relations, and transport (around 50\%). This was the case for $34.9 \%$ of clinician rated unmet needs $(\mathrm{N}=680)$; in particular in the domains daytime activities, psychotic symptoms, alcohol, drugs, intimate relations, sexual expression, and money (also around 40-50\%). Thus, most unmet needs, according to both perspectives, made a transition to no need or met need.

Table 3 about here 
Looking back retrospectively, more than half of the unmet needs at follow-up were new (54.5\% for patient rated and $51.9 \%$ for clinician rated needs). Substantial proportions (30.1\% and $23.1 \%$ respectively) were rated as no need at baseline. Generally, unmet needs in the domains of intimate relationships, sexual expression, company, day-time activities, physical health, and psychological distress were rated by boths rather frequently as new. Also, substantial proportions of patients without an unmet need at baseline had at least one unmet need at follow-up (31\% according to patients and 38\% according to clinicians). The same applies to patients with at least one unmet need at baseline and none one year later ( $24 \%$ according to patients and $29 \%$ according to clinicians). Change in these proportions was not related to the treatment condition.

Table 4 about here

Agreement (Cohen's Kappa) between the patient and clinician on individual needs at baseline was on average .27 , which raised to .30 at follow-up. This actually did not reflect a better agreement on unmet needs; on the contrary, the average proportion of agreement of patients with their clinicians on all unmet needs dropped from $40 \%$ to $30 \%$, and the same occurred with the agreement of the clinicians with the patients on unmet needs $(33 \%$ at baseline to $29 \%$ at follow-up). One could argue whether agreement between patient and clinician on unmet needs at baseline would increase the chance on a met or no need later on, and whether the treatment condition would made a difference (the DIALOG condition would be expected to do better). However, it appeared that in those cases in which patient and clinician agreed on unmet need status at baseline (on average $16 \%$, range from $0 \%$ to $40 \%$, in particular more frequently with respect to daytime activities, physical health, psychotic symptoms, psychological distress, copmpany, intimate relationships, and sexual 
expression), no association with a met need status at follow-up showed up, and without a differential effect of treatment condition.

Table 5 about here

\section{Discussion}

This one-year follow-up study of prevalence of patient rated as well as clinician rated individual needs for care among 320 patients and their 98 key workers in community health centers in four countries showed a rather stable number of met needs but a statistically significantly decreasing number of unmet needs and an increasing number of patients without any unmet need. This occurred in all four centres. Most unmet needs, nearly two thirds, according to both patients and clinicians, were met or had disappeared at the time of follow-up: only four patient rated unmet needs of psychotic symptoms, company, intimate relations, and transport were relatively persistent (around 50\%), while for clinician rated unmet needs this was the case for daytime activities, psychotic symptoms, alcohol, drugs, intimate relations, sexual expression, and money (40-50\%). The incidence of unmet needs over one year was relatively high considering the chronic illness duration of about 18 years and the existence of multiple problems: $52-55 \%$ of the follow-up unmet needs were new. Finally, the concordance between met and unmet needs at baseline and follow-up and the agreement between patients and their clinicians at both occasions were low and virtually absent. There was no indication that treatment condition (usual care with or without the novel intervention DIALOG) had a discernable influence on the reduction or prevention of individual unmet needs. Latter outcome seems somewhat discrepant with the result of the reported overall effect of the DIALOG intervention on the reduction of unmet needs which -using the sum index- is indeed not satistically significant anymore $(P=.07)$, probably due 
to the reduced power (from $\mathrm{N}=502$ to 320 ) with the exclusion of two centres with the greatest effect sizes (Granada and London). However, the focus of this paper is more on individual needs.

The strength of this study is a high inclusion rate of people with long term problems in community mental health care settings with a low number lost to follow-up (6-8\%) and only a few changes of clinicians affecting a low number of patients [26]. One limitation is the use of exclusion criteria for the sake of the clinical trial regarding diagnosis (only schizophrenia or related psychotic disorders), physical handicaps or organic illness, age, or insufficient contact with care coordinator, which might restrict generalization to the whole patient population in community care. The post hoc nature of the present analysis allows for tentative conclusions only.

The agreement between patient and clinician was rather small, although both were interviewed by the same investigators who were properly trained and monitored. The interrater reliability of CAN is well established [7,17,22]; this study on case vignettes: Kappa $.90)$ and found to be good to excellent, at least on the level of summary measures with a slight fall-off for unmet needs, while the test-retest and the inter-rater reliability with regard to individual items of needs appeared to be much less. The agreement between patient and staff ratings of needs generally is quite moderate and particularly insufficient as to individual items of unmet needs [32] (also this study: proportion between 29 and 40\%; Kappa between .14-.30). This applies also to the agreement between patient and his/her carer [3]. An observation is that the follow-up ratings of needs have been made by the investigators without explicitly taking into account the baseline measurement. The assessment of the status of unmet needs could therefore be strengthened by additional 
probing and checking of the reasons why that status has changed over time in the eye of the beholder. Another consideration, based on the study of Drukker et al [4], is to assess needs not by an independent researcher but by both parties involved together; this may yield ratings which better reflect the clinical relevance of a problem and the validity of its need status (met or unmet) over time (see also Macpherson et al [15] ). It is possibly a limitation in our study that the need assessment was research oriented and not used as a clinical tool to guide the intervention.

The prevalence rate of met and unmet needs in our study is in line with earlier research including the (significant) tendency towards lower numbers at follow-up [12,34], although after longer periods this may be reversed (see [1] on the 10 year follow-up in Sweden). Overall these findings are more or less consistent with the CAN literature. However, our data suggest an overall high sensitivity to change and a high incidence of new individual unmet needs among patients with chronic psychiatric and social problems, no matter whether these were rated by the patient or the clinician. The same variability of selfperceived unmet needs was found in a Dutch study [19] among 109 schizophrenia patients with a follow-up of 18 months; most unmet needs disappeared, while only those relating to day-time activities, psychological distress, and company were relatively stable (about 50\% of the cases).

Nevertheless this is rather surprising and possibly an underestimated phenomenon. Wennström and Wiesel [33] observed over a period of six years that the mean number of (unmet) needs did not change much (about 6.3 for total and 1.5 for unmet needs), most (82\%) needs in 1997 were (still) met or had disappeared in 2003 and more than $70 \%$ of needs occurring after baseline were met at follow-up. They see this as an indication of effective care that successfully meets the health needs of the patients and argued that 
summary indices of needs are not a valid outcome measure in routine mental health care because they conceal important changes over time on the individual level of needs.

Drukker et al [5] also found that specific unmet needs in the area of accommodation, household, self care, alcohol or drugs were more likely met after about 19 months than unmet needs in the realm of psychopathology and daytime activities.

Such transitions from unmet need to no or met need maybe due to various sources, such as general or specific interventions from mental health services, psychological adjustment processes, life changes, time effect, etc. Do our findings (and of others) provide indications that usual care includes such an effective rehabilitative effort that unmet needs are likely to disappear? Can it be argued that community mental health care in western industrialised countries is so advanced that we could expect such changes in unmet needs over time? On the one hand, Fakhoury \& Priebe [6] criticised community mental health care and urged toward establishing better practice to support continuity of care and guided sheltered living. On the other hand Kovess-Masféty et al [12] demonstrated in their follow-up study (with another instrument, the Needs for Care Assessment, [2]) among 391 in-, out-, and daypatients with schizophrenia in six European centres that the number of proposed interventions was not related to need status but that the availability of community based treatment (outpatient and rehabilitation services) seems indeed to be related to (less) unmet needs. And Kallert and Leisse [10] showed a trend towards rating unmet needs (e.g. communication, slowness, and underactivity) as not meetable over time. This option of rating a need as no meetable is not available in the CANSAS.

Thus so far much evidence of the effectiveness of regular community mental health care is still lacking and the concept of unmet needs as a firm outcome criterion is probably premature. Need is a rather subjective concept and perfect agreement between the patient 
and his/her clinician or carer may not be expected but some consistency over time in needs is necessary for making sense in clinical practice. Some lack of agreement between patient and his/her clinician or even the carer is not surprising but in case of such an overwhelming lack, even more so at a second time of measurement is worrysome. It is then difficult to give one perspective priority above the other. The more so because of the disappearance of most - patient as well as clinician rated - unmet needs in a relatively very short time in a stable chronic patient population without much relationship to the novel intervention which was particularly designed to meet specific needs. This could have been a kind of validation of the transition of unmet needs to met needs. Could it then be partly ascribed to conceptual issues? Priebe et al. [24] argue that the concept of need inappropriately simplifies the actual process of clinical decision making. They propose a way-out by clearly identifying problems, specifying goals, and choosing interventions of which the outcomes should be regularly be monitored. This might, for example, be better guaranteed by a more complex instrument like the Needs of Care Assessment [2,16], which may partly solve these conceptual issues but carries with it other problems of training, implementation, rating, and the perspective of one beholder (the clinician).

Our retrospective secondary analysis should be followed by prospective quantitative investigations using repeated measures to study the association between intervention and consequent impact on need status in specific domains, to assess whether the CAN is indeed sensitive to change, a true change or due to measurement error. Also more qualitative domain-specific assessment of change is worthwhile in order to better understand what it means when an unmet need changes or emerges, and to establish the domains which change due to health service intervention compared with the domains which change for other reasons. 


\section{APPENDIX}

The Mediating Community Care Group includes the following: Granada: Marta Ribes

Leyva, Maria F Soriano Peña, Beatriz Arroyo de Domingo. Groningen: Kerstin Wolters, Aukelien Mulder, Jappie Tiersma. London: Rakhee Haque. Lund: Tommy Björkman.

Mannheim: Marita Reichenbacher, Anette Axt. Zurich: Patric Meyer, Minka Burgi.

We are indebted to the clinicians and patients who took part in the Mediating Community

Care study, to Dr Michael Dewey for statistical advice, and to Dr Patrick Healey and Greg

Mills for software development and technical support. 
Reference List

1. Arvidsson H (2008) The development of needs in a group of severely mentally ill : A 10-year follow-up study after the 1995 Swedish mental health care reform. Soc Psychiatry Psychiatr Epidemiol

2. Brewin CR, Wing JK, Mangen SP, Brugha TS, MacCarthy B (1987) Principles and practice of measuring needs in the long-term mentally ill: the MRC needs for care assessment. Psychol Med 17:971-981

3. Cleary M, Freeman A, Hunt GE, Walter G (2006) Patient and carer perceptions of need and associations with care-giving burden in an integrated adult mental health service. Soc Psychiatry Psychiatr Epidemiol 41:208-214

4. Drukker M, Bak M, Driessen G, Van OJ, Delespaul PA (2007) Can the "Camberwell Assessment of Need" predict changes in care consumption? Tijdschr Psychiatr $49: 305-314$

5. Drukker M, van DK, Bak M, Mengelers R, Van OJ, Delespaul P (2008) The use of the Camberwell Assessment of Need in treatment: what unmet needs can be met? Soc Psychiatry Psychiatr Epidemiol 43:410-417

6. Fakhoury WK, Priebe S (2002) The process of deinstitutionalization: an international overview. Curr Opin Psychiatry 15:187-192

7. Hansson L, Bjorkman T, Svensson B (1995) The assessment of needs in psychiatric patients. Interrater reliability of the Swedish version of the Camberwell Assessment of Needs instrument and results from a cross-sectional study. Acta Psychiatr Scand $92: 285-293$

8. Hansson L, Vinding HR, Mackeprang T, Sourander A, Werdelin G, Bengtsson-Tops A, Bjarnason O, Dybbro J, Nilsson L, Sandlund M, Sorgaard K, Middelboe T (2001) 
Comparison of key worker and patient assessment of needs in schizophrenic patients living in the community: a Nordic multicentre study. Acta Psychiatr Scand 103:45-51

9. Joska J, Flisher AJ (2005) The assessment of need for mental health services. Soc Psychiatry Psychiatr Epidemiol 40:529-539

10. Kallert TW, Leisse M (2001) Schizophrenic patients' normative needs for community-based psychiatric care: an evaluative study throughout the year following hospital release in the Dresden region. Soc Psychiatry Psychiatr Epidemiol 36:1-12

11. Kay SR, Fiszbein A, Opler LA (1987) The positive and negative syndrome scale (PANSS) for schizophrenia. Schizophr Bull 13:261-276

12. Kovess-Masféty V, Wiersma D, Xavier M, Caldas de Almeida JM, Carta MG, Dubuis J, Lacalmontie E, Pellet J, Roelandt JL, Torres-Gonzalez F, Moreno Kustner B, Walsh D (2006) Needs for care among patients with schizophrenia in six European countries: a one-year follow-up study. Clin Pract Epidemol Ment Health 2:22

13. Lasalvia A, Ruggeri M, Mazzi MA, Dall'Agnola RB (2000) The perception of needs for care in staff and patients in community-based mental health services. The SouthVerona Outcome Project 3. Acta Psychiatr Scand 102:366-375

14. Lockwood A, Marshall M (1999) Can a standardized needs assessment be used to improve the care of people with severe mental disorders? A pilot study of 'needs feedback'. J Adv Nurs 30:1408-1415

15. MacPherson R, Gregory N, Slade M, Foy C (2007) Factors associated with changing patient needs in an assertive outreach team. Int J Soc Psychiatry 53:389-396

16. Marshall M, Hogg LI, Gath DH, Lockwood A (1995) The Cardinal Needs Schedule-a modified version of the MRC Needs for Care Assessment Schedule. Psychol Med $25: 605-617$ 
17. McCrone P, Leese M, Thornicroft G, Schene AH, Knudsen HC, Vazquez-Barquero JL, Lasalvia A, Padfield S, White IR, Griffiths G (2000) Reliability of the Camberwell Assessment of Need--European Version. EPSILON Study 6. European Psychiatric Services: Inputs Linked to Outcome Domains and Needs. Br J Psychiatry Suppl 177:s34-s40

18. McGuffin P, Farmer A, Harvey I (1991) A polydiagnostic application of operational criteria in studies of psychotic illness. Development and reliability of the OPCRIT system. Arch Gen Psychiatry 48:764-770

19. Meijer CJ, Koeter MWJ, Schene AH (2005) Temporal stability of needs for care and the relation with quality of life: a longitudinal study among patients with schizophrenia. In: Meijer CJ ed. Quality of life and needs for care of patients with schizophrenia (Thesis). University of Amsterdam, Amsterdam, pp. 60-72

20. Nguyen TD, Attkisson CC, Stegner BL (1983) Assessment of patient satisfaction: development and refinement of a service evaluation questionnaire. Eval Program Plann 6:299-313

21. O'Leary D, Webb M (1996) The need for care assessment - A longitudinal approach. Psychiatr Bull 20:134-136

22. Phelan M, Slade M, Thornicroft G, Dunn G, Holloway F, Wykes T, Strathdee G, Loftus L, McCrone P, Hayward P (1995) The Camberwell Assessment of Need: the validity and reliability of an instrument to assess the needs of people with severe mental illness. Br J Psychiatry 167:589-595

23. Priebe S, Fakhoury WK, Hoffmann K, Powell RA (2005) Morale and job perception of community mental health professionals in Berlin and London. Soc Psychiatry Psychiatr Epidemiol 40:223-232 
24. Priebe S, Huxley P, Burns T (1999) Who needs needs? European Psychiatry 14:186188

25. Priebe S, Huxley P, Knight S, Evans S (1999) Application and results of the Manchester Short Assessment of Quality of Life (MANSA). Int J Soc Psychiatry $45: 7-12$

26. Priebe S, Mccabe R, Bullenkamp J, Hansson L, Lauber C, Martinez-Leal R, Rössler W, Salize HJ, Svensson B, Torres-Gonzales F, Brink van den RHS, Wiersma D, Wright DJ (2007) Structured patient-clinician communication and one-year outcome in community mental health care: A cluster randomised controlled trial. $\mathrm{Br} \mathrm{J}$ Psychiatry in press:

27. Ruggeri M, Leese M, Slade M, Bonizzato P, Fontecedro L, Tansella M (2004) Demographic, clinical, social and service variables associated with higher needs for care in community psychiatric service patients. The South Verona Outcome Project 8. Soc Psychiatry Psychiatr Epidemiol 39:60-68

28. Salize HJ, Kustner BM, Torres-Gonzalez F, Reinhard I, Estevez JF, Rossler W (1999) Needs for care and effectiveness of mental health care provision for schizophrenic patients in two European regions: a comparison between Granada (Spain) and Mannheim (Germany). Acta Psychiatr Scand 100:328-334

29. Slade M, Beck A, Bindman J, Thornicroft G, Wright S (1999) Routine clinical outcome measures for patients with severe mental illness: CANSAS and HoNOS. Br J Psychiatry 174:404-408

30. Slade M, Leese M, Taylor R, Thornicroft G (1999) The association between needs and quality of life in an epidemiologically representative sample of people with psychosis. Acta Psychiatr Scand 100:149-157 
31. Slade M, Phelan M, Thornicroft G (1998) A comparison of needs assessed by staff and by an epidemiologically representative sample of patients with psychosis. Psychol Med 28:543-550

32. Slade M, Phelan M, Thornicroft G, Parkman S (1996) The Camberwell Assessment of Need (CAN): comparison of assessments by staff and patients of the needs of the severely mentally ill. Soc Psychiatry Psychiatr Epidemiol 31:109-113

33. Wennström E, Wiesel FA (2006) The Camberwell assessment of need as an outcome measure in routine mental health care. Soc Psychiatry Psychiatr Epidemiol 41:728733

34. Wiersma D (2006) Needs of people with severe mental illness. Acta Psychiatr Scand Suppl 113:115-119

35. Wiersma D, Giel R, Jong de A, Nienhuis FJ, Slooff CJ (1996) Assessment of the need for care 15 years after onset of a Dutch cohort of patients with schizophrenia, and an international comparison. Soc Psychiatry Psychiatr Epidemiol 31:114-121 
Table 1. Baseline Sociodemographic Characteristics of Patients and their Clinicians, means (SD) and proportions (\%).

\begin{tabular}{|c|c|}
\hline Patients $(\mathrm{N}=320)$ & \\
\hline Mean age (yr) & $42.8(10.8)$ \\
\hline Male & $67.2 \%$ \\
\hline Marital status (single) & $70.3 \%$ \\
\hline Employed (incl. Sheltered work) & $42.5 \%$ \\
\hline Unemployed & $27.5 \%$ \\
\hline Other & $30.0 \%$ \\
\hline \multicolumn{2}{|l|}{ Diagnosis } \\
\hline Undifferentiated schizophrenia & $39.1 \%$ \\
\hline Paranoid schizophrenia & $24.1 \%$ \\
\hline Other (schizo-affective, delusional) & $17.4 \%$ \\
\hline Other non-organic psychosis & $19.4 \%$ \\
\hline Mean length of illness (yr) & $17.8(9.8)$ \\
\hline Mean number hospital admissions & $6.7(8.5)$ \\
\hline Quality of Life & $4.8(0.9)$ \\
\hline Satisfaction with treatment & $25.4(4.0)$ \\
\hline \multicolumn{2}{|l|}{ Symptomatology (PANSS) } \\
\hline Positive subscale & $14.7(5.8)$ \\
\hline Negative subscale & $16.6(6.7)$ \\
\hline General subscale & $32.6(9.6)$ \\
\hline \multicolumn{2}{|l|}{ Clinicians $(\mathrm{N}=98)$} \\
\hline Mean age (yr) & $45.0(8.9)$ \\
\hline Male & $37.3 \%$ \\
\hline \multicolumn{2}{|l|}{ Profession } \\
\hline Psychiatric nurse & $45.9 \%$ \\
\hline Social worker & $21.4 \%$ \\
\hline Psychiatrist & $10.2 \%$ \\
\hline Psychologist & $5.1 \%$ \\
\hline Other & $17.3 \%$ \\
\hline Mean length of service (yr) & $14.3(8.7)$ \\
\hline Average caseload & $21.3(13.3)$ \\
\hline
\end{tabular}


Table 2. Prevalence of patient rated and clinician rated needs for care (sum indices) at baseline and 1-year follow-up, means and standard deviations (SD).

\begin{tabular}{|c|c|c|c|c|c|}
\hline $\begin{array}{r}\text { Patient rated } \\
\text { needs }(N=294)\end{array}$ & $\begin{array}{c}\text { Baseline } \\
\text { (SD) }\end{array}$ & $\begin{array}{c}\text { Follow-up } \\
\text { (SD) }\end{array}$ & $\begin{array}{c}P \\
(\mathrm{t}-\mathrm{test} / \mathrm{chi}- \\
\text { square) }\end{array}$ & $\begin{array}{c}\text { Correlation } \\
\text { (P) }\end{array}$ & $\begin{array}{c}\text { Difference } \\
\text { (SD) }\end{array}$ \\
\hline Total Needs & $6.8(3.1)$ & $6.6(2.9)$ & .41 & $.44(.000)$ & $.15(3.2)$ \\
\hline Met Needs & $4.8(2.7)$ & $5.0(2.8)$ & .22 & $.37(.000)$ & $-.22(3.1)$ \\
\hline Unmet Needs & $2.0(2.8)$ & $1.6(1.9)$ & .001 & $.59(.000)$ & $.37(1.9)$ \\
\hline $\begin{array}{r}\text { Proportion of } \\
\text { patients }\end{array}$ & & & & & \\
\hline $\begin{array}{r}\text { without unmet } \\
\text { needs }\end{array}$ & $34.0 \%$ & $39.1 \%$ & .000 & & \\
\hline
\end{tabular}

\begin{tabular}{rccccc} 
Clinician rated & $\begin{array}{c}\text { Baseline } \\
\text { needs (N=302) }\end{array}$ & $\begin{array}{c}\text { Follow-up } \\
\text { (SD) }\end{array}$ & $\begin{array}{c}\boldsymbol{P} \\
\text { (SD) }\end{array}$ & $\begin{array}{c}\text { Correlation } \\
\text { (t-test/chi- } \\
\text { square) }\end{array}$ & $\begin{array}{c}\text { Difference } \\
(\boldsymbol{P})\end{array}$ \\
\hline Total Needs & $8.3(3.7)$ & $8.0(3.7)$ & .06 & $.59(.000)$ & $.37(3.4)$ \\
Met Needs & $6.0(3.2)$ & $6.3(3.4)$ & .16 & $.49(.000)$ & $-.27(3.3)$ \\
Unmet Needs & $2.3(2.6)$ & $1.7(2.1)$ & .000 & $.46(.000)$ & $.63(2.5)$ \\
Proportion of & & & & & \\
patients & & $39.3 \%$ & .000 & & \\
without unmet & $31.3 \%$ & & & &
\end{tabular}


Table 3. Sensitivity to change of baseline Individual Unmet Needs at 1-yr follow-up

Status of Individual Needs at 1 yr follow-up

\begin{tabular}{rcccc}
\hline $\begin{array}{r}\text { Unmet Needs } \\
\text { at baseline: }\end{array}$ & No Need & Met Need & Unmet Need & Total \\
Patient rated & $209(35.8 \%)$ & $159(27.2 \%)$ & $216(37.0 \%)$ & $\mathbf{5 8 4}(\mathbf{1 0 0} \%)$ \\
Clinician rated & $199(29.3 \%)$ & $244(35.9 \%)$ & $237(34.9 \%)$ & $\mathbf{6 8 0}(\mathbf{1 0 0} \%)$ \\
\hline
\end{tabular}


Table 4. Baseline Status of Individual Unmet Needs at 1-year follow-up

\begin{tabular}{|c|c|c|}
\hline $\begin{array}{l}\text { Need Status } \\
\text { at baseline: }\end{array}$ & $\begin{array}{l}\text { Patient rated Unmet } \\
\text { Needs at follow-up }\end{array}$ & $\begin{array}{l}\text { Clinician rated Unmet } \\
\text { Needs at follow-up }\end{array}$ \\
\hline No need & $143(30.1 \%)$ & $114(23.1 \%)$ \\
\hline Met need & $116(24.4 \%)$ & $143 \quad(28.9 \%)$ \\
\hline Unmet need & $216 \quad(45.5 \%)$ & $237 \quad(48.0 \%)$ \\
\hline Total & $475(100 \%)$ & $494(100 \%)$ \\
\hline
\end{tabular}


Table 5. Agreement between Patient rated and Clinician rated Needs, at baseline and 1 year follow-up (Spearman correlation and Cohen's Kappa)

\title{
Correlation
}

\author{
Baseline ( $=317)$

$\begin{array}{rr}\text { Sum index of Total Needs } & .36 \\ \text { Sum index of Unmet Needs } & .46\end{array}$ \\ Average over Individual Unmet Needs (3 categories) .34 (Rho) or .27 (Kappa) \\ Follow-up (N=289)

$\begin{array}{rc}\text { Sum index of Total Needs } & .46 \\ \text { Sum index of Unmet Needs } & .34 \\ \text { Unmet Needs (3 categories) } & .34 \text { (Rho) or .30 (Kappa) }\end{array}$

Baseline: Mean proportion agreement on individual needs of

$$
\begin{array}{ll}
\text { patient with clinician } & 40 \% \\
\text { clinician with patient } & 33 \%
\end{array}
$$

Follow-up: Mean proportion agreement on individual needs of

$\begin{array}{ll}\text { patient with clinician } & 30 \% \\ \text { clinician with patient } & 29 \%\end{array}$


Paul Bebbington

Editor-in-Chief

Social Psychiatry and Psychiatric Epidemiology

August 7, 2008

Dear Paul,

Thanks for having me resubmit our paper on unmet needs for care. As suggested I have reviewed last couple of years of SPPE on relevant publications and as you will see I have added four (recent and interesting) papers (Arvidson 2008, Drukker 2008, Clearly 2006 and Joska 2005). Of course, this produced changes in the list of references in the text.

I will go through the reviewers comments (7) and indicate the textual changes and modifications by page.

Frontpage 1: wordcount and affiliation updated Page 13 /14: I added some lines on the new literature (1 and 5) and moved a bit with the text, just to improve the line of reasoning.

1) include a table which lists all the need domains and the change over the year.

Of course, I have all the data on individual needs at baseline and at follow-up, including the changes in need status of the baseline unmet needs (persistency) and the new unmet needs (incidence), for both patient and keyworker rated needs. IN an earlier version of the manuscript I used two extra tables to illustrate on individual need level what is summarized in table 3 and 4 in the submitted paper. I am inclined not to do this because the reader gets a bit lost in all the details ( 22 needs $x 6$ columns of figures). I have tried to highlight the main findings. Would it not be better to have these tables just 'available on request'?

2) comment more on the limited agreement and emphasize that need is a subjective concept and that different perceptions are to be expected.

The point is well taken, I have mentioned this in the discussion, see page 15 inserted 'Need is a rather subjective concept and perfect agreement between the patient and his/her clinician or carer may not be expected but some consistency over time in needs is necessary for making sense in clinical practice'

3) More attention needs to be given to the fact this was a multicentre study, more information is needed re any significant differences in the services and results from the different sites.

In a multicentre study there are always differences between sites. This is also the case with number of needs and also unmet needs. The trend of decreasing nember of (unmet) needs occurred in all four centres (I addedd this to the discussion see page 11 inserted 'This occurred in all four centres'). The difference also applies to the services (availability of staff, kind and number of therapeutic activities, number of contacts, hospitalizations, duration of care, etc). It is difficult to explain these 
differences. One has to accept that countries differ in these respects and that each centre might not even be representative for the whole country. There are two papers from this European study in submission one about utilization of care and one about therapeutic activities. A conclusion is that differences between the (six) centres of contact duration and frequency in mental health services have little impact on patient outcome (e.g. unmet needs, quality of life). So, it deserves nearly a separate paper to elaborate this point properly and probably without substantal influence on the message of the current paper. I hesitate to dwell on this subject too much. I hope you can agree with me on this point.

4) Table 1 - I am not sure why clinician job satisfaction is included as it does not seem relevant to anything else in the paper

Right, I removed it from the table, not relevant here.

5) It is not clear why data are reported from 4 of the 6 study sites and not 6 (excluding the larger centres)

Simply, two centres, Granada and London, decided for logistical reasons and lack of research resources not to interview the patient on needs for care. It was clear from the beginning that they would not do it, also it was not essential for the main research question. Is acknowledged in the text see page 6 inserted 'Logistical reasons and lack of research resources prevented such an assessment in Granada and London'.

6) A key finding is that although the numbers of unmet needs rated by staff and by patient is similar, the types of needs rated are rather different - but this is far from new and studies by slade et al and by Ruggeri et al have previously reported this.

$\mathrm{OK}$, it is acknowledged in the paper, also added that there are the same disagreements between patient and carer (Clearly et al 2006), see page 12/13 inserted 'This applies also to the agreement between patient and his/her carer [3] '

7) The conclusion that CANSAS is less suitable for treatment outcome measurement is not fully justified as the authors argue this on the basis of patient-staff divergence of views. Rather the authors might address whether one source or the other might be given salience or how to make sense and interpret these differing views- and how to validate this finding. Indeed it might be argued that using only staff rated outcomes might not represent patient rated aspects of treatment impact.

Correct, but the main point is that for both raters and perspectives the finding is that in case of a chronic patient population with schizophrenia unmet needs come and go within a short period of time (1 year) without (a) much persistency, without (b) much relationship to a mental health intervention or specific therapeutic interventions and without (c) much agreement between keyworker and patient, although the latter might be related to methodological frailty. I am not surprised that there is some lack of agreement but that the lack is so overwhelming and even more at a second time of measurement. These three aspects worry me. Taken into account differing perspectives is essential in a therapeutic relationship but there must be a coordinating person who brings them together. And I was concerned that that has not happened yet in community mental health care in the various European countries while the DIALOG intervention was particularly designed to meet individual unmet needs. 
I have tried to accommodate this comment in the discussion. See page 15 inserted 'Some lack of agreement between patient and his/her clinician or even the carer is not surprising but in case of such an overwhelming lack, even more so at a second time of measurement is worrysome. It is then difficult to give one perspective priority above the other. The more so because of the disappearance of most-patient as well as clinician rated-unmet needs in a relatively very short time in a stable chronic patient population without much relationship to the novel intervention which was particularly designed to meet specific needs. This could have been a kind of validation of the transition of unmet needs to met needs'.

Looking forward to hear from you.

On behalf of all the authors

Kind regards

Durk Wiersma 